\title{
Healthcare-Associated Pneumonia among Hospitalized Patients: Is It Different from Community Acquired Pneumonia?
}

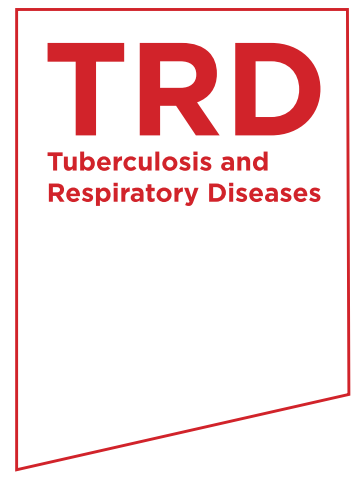

\author{
Gil Myung Seong, M.D. ${ }^{1}$, Miok Kim, M.D., Ph.D. ${ }^{1}$, Jaechun Lee, M.D., Ph.D. ${ }^{1}$, Jong Hoo Lee, M.D., \\ Ph.D. ${ }^{1}$, Sun Young Jeong, M.D., Ph.D. ${ }^{2}$, Yunsuk Choi, M.D., Ph.D. ${ }^{3}$ and Woo Jeong Kim, M.D., Ph.D. ${ }^{4}$ \\ Departments of ${ }^{1}$ Internal Medicine, ${ }^{2}$ Radiology, ${ }^{3}$ Anesthesia and Pain Medicine, and ${ }^{4}$ Emergency Medicine, Jeju National \\ University School of Medicine, Jeju, Korea
}

Background: The increasing number of outpatients with multidrug-resistant (MDR) pathogens has led to a new category of pneumonia, termed healthcare-associated pneumonia (HCAP). We determined the differences in etiology and outcomes between patients with HCAP and those with community-acquired pneumonia (CAP) to clarify the risk factors for HCAP mortality.

Methods: A retrospective study comparing patients with HCAP and CAP at Jeju National University Hospital. The primary outcome was 30-day mortality.

Results: A total of 483 patients (208 patients HCAP, 275 patients with CAP) were evaluated. Patients with HCAP were older than those with CAP (median, 74 years; interquartile range [IQR], 65-81 vs. median, 69 years; IQR, 52-78; $\mathrm{p}<0.0001$ ). Streptococcus pneumoniae was the major pathogen in both groups, and MDR pathogens were isolated more frequently from patients with HCAP than with CAP ( $18.8 \%$ vs. $4.9 \%, \mathrm{p}<0.0001)$. Initial pneumonia severity was greater in patients with HCAP than with CAP. The total 30-day mortality rate was $9.9 \%$ and was higher in patients with HCAP based on univariate analysis (16.3\% vs. 5.1\%; odds ratio (OR), 3.64; 95\% confidence interval (CI), 1.90-6.99; p<0.0001). After adjusting for age, sex, comorbidities, and initial severity, the association between HCAP and 30-day mortality became non-significant (OR, 1.98; 95\% CI, 0.94-4.18; $\mathrm{p}=0.167$ ).

Conclusion: HCAP was a common cause of hospital admissions and was associated with a high mortality rate. This increased mortality was related primarily to age and initial clinical vital signs, rather than combination antibiotic therapy or type of pneumonia.

Keywords: Pneumonia; Anti-Bacterial Agents; Drug Resistance; Mortality

Address for correspondence: Miok Kim, M.D., Ph.D.

Department of Internal Medicine, Jeju National University Hospital, 15

Aran 13-gil, Jeju 690-767, Korea

Phone: 82-64-717-1614, Fax: 82-64-717-1131

E-mail: miohkim@hanmail.net

Received: Nov. 20, 2012

Revised: Jan. 20, 2014

Accepted: Jan. 29, 2014

(c) It is identical to the Creative Commons Attribution Non-Commercial License (http://creativecommons.org/licenses/by-nc/3.0/).

Copyright (c) 2014

The Korean Academy of Tuberculosis and Respiratory Diseases.

All rights reserved.

\section{Introduction}

Pneumonia is typically classified as community-acquired pneumonia (CAP), hospital-acquired pneumonia (HAP), or ventilator-associated hospital-acquired pneumonia (VAP). However, over the past few decades, some patients presenting as outpatients with pneumonia have been infected with multidrug-resistant (MDR) pathogens such as Pseudomonas aeruginosa, methicillin-resistant Staphylococcus aureus, and extended-spectrum $\beta$-lactamase producing Enterobacteriaceae $^{1}$. The potential involvement of these MDR pathogens has led to a new category of pneumonia, termed healthcare-associated pneumonia (HCAP). In 2005, the American Thoracic 
Society (ATS) and the Infectious Disease Society of America (IDSA) published the first guidelines for managing adults with $\mathrm{HCAP}^{2}$. In these guidelines, HCAP is included in the spectrum of HAP and VAP, and all patients with HCAP require therapy with dual antipseudomonal antibiotics plus linezolid or vancomycin for MDR pathogens.

Although the new pneumonia classification system has been helpful for determining empirical antibiotic strategies, it is not without its disadvantages. First, because of a lack of large-scale prospective studies and limited epidemiological data, the clinical outcomes of the 2005 ATS/IDSA guidelines are still under discussion. Not all MDR pathogens are associated with all risk factors. In addition, risk factors for an MDR pathogen infection do not preclude the development of pneumonia caused by the typical CAP pathogens ${ }^{3}$.

\section{Materials and Methods}

This was a retrospective observational study conducted at Jeju National University Hospital, a 500-bed teaching hospital in Jeju, Republic of Korea, between January 2010 and December 2011. All consecutive patients with pneumonia admitted to the hospital through the emergency or outpatient department were eligible. One of the investigators (G.M.S) reviewed all 1,754 patients hospitalized at the Department of Respiratory and Allergy during the 2-year period to identify appropriate patients. Patients with HAP, those on a home mechanical ventilator, patients referred after antibiotic administration, and patients with human immunodeficiency virus infection or organ transplantation were excluded. We considered that patients who fulfilled the HCAP criteria but developed pneumonia within 10 days after discharge as having developed HAP. We classified study patients into CAP and HCAP groups, and compared clinical characteristics, severity, pathogen distribution, and outcomes between the two groups. Our study protocol was approved by the Institutional Review Board of Jeju National University Hospital (IRB no. 2012/08002).

\section{Definition of pneumonia}

Patients with pneumonia were defined as those presenting with a new radiographic infiltrate and at least two of the following symptoms or signs: cough, sputum production, hemoptysis, dyspnea, fever, pleuritic chest pain, or signs consistent with pneumonia on physical examination ${ }^{4}$. HCAP and CAP were defined according to the ATS/IDSA guidelines ${ }^{2,5}$. The HCAP group included patients with any of the following: 1) hospitalization for $\geq 2$ days during the preceding 90 days; 2 ) residence in a nursing home or long-term care facility; 3 ) recent intravenous antibiotic therapy, chemotherapy, or wound care within the past 30 days before entering the study; 4) longterm dialysis, including hemodialysis and peritoneal dialysis, within 30 days of entering the study. The diagnosis and type of pneumonia were verified twice from the medical records by one of the investigators (G.M.S. or M.K.).

\section{Microbiological evaluation}

Recommended initial microbiological investigations were sputum and blood cultures, Legionella and pneumococcal urine antigen testing, an antibody titer for Mycoplasma pneumoniae, and stains and cultures in selected patients. Specimens acceptable for positive culture results included sputum, tracheal aspirate, bronchoscopic bronchoalveolar lavage fluid, and blood. Blood culture results were accepted if the same microorganism was also identified in a respiratory specimen or if no other source for the positive blood culture was identified. Additionally, a positive Legionella urine antigen result, an antibody titer for an atypical pathogen that changed to 4-fold or converted to positive, and a positive polymerase chain reaction for Mycobacterium tuberculosis were considered to indicate etiological pathogens.

Antibiotic therapy was classified as being inappropriate if the initially prescribed antibiotics were not active against the identified pathogens, based on in vitro susceptibility testing. Exceptionally, atypical pathogens such as M. pneumoniae, Chlamydophila species, and Legionella species were considered fully susceptible to fluoroquinolones or macrolides, and M. tuberculosis was excluded from being judged appropriately, because it requires a special antibiotic regimen.

\section{Severity evaluation and outcomes}

All patients were assessed for risk at admission using the Pneumonia Severity Index (PSI) and CURB-65 scores ${ }^{6,7}$. Patients were followed for 30 days from the date of admission. We recorded the 30-day mortality and the need for admission to the intensive care unit, mechanical ventilation, and/or vasopressor support. Initial treatment failure was defined as death during initial treatment or a change from the initial antibiotic to another drug after 48 hours because of clinical instability (e.g., lack of response, worsening of fever, or requirement for mechanical ventilation or vasopressors).

\section{Statistical analysis}

All statistical analyses were performed using PASW version 17 (SPSS Inc., Chicago, IL, USA). A level of $\mathrm{p}<0.05$ was considered to indicate statistical significance. The $\chi$-squared test was used to compare categorical variables. Continuous variables were analyzed using Student's t-test or the Mann-Whitney U test. Multivariate logistic regression analysis was performed to identify independent risk factors associated with 30-day mortality, as measured by the adjusted odds ratio (AOR) with 95\% confidence intervals (CIs). The 30-day mortality was the 
dependent variable, and all potential risk factors with p-values $<0.2$ in the univariate analysis were independent variables in the multivariate logistic regression model.

\section{Results}

\section{Patients}

A total of 483 patients were evaluated (208 patients with HCAP and 275 with CAP) (Figure 1). Most of these patients were admitted due to a recent admission (54.3\%) or residence in a nursing home (48.1\%) (including overlapping cases). Eighty-four patients (40.4\%) had more than two risk factors. The demographic and baseline clinical characteristics of the patients with HCAP and CAP are presented in Table 1. Patients with HCAP were older and had a lower body mass index than patients with CAP. No gender differences were observed between the groups, but comorbidities such as cancer, congestive heart failure, cerebrovascular disease, and dementia occurred more frequently in patients with HCAP.

\section{Microbiology and antibiotic treatments}

A positive microbiological diagnosis was made in 51.3\% of the patients with HCAP compared with $39.2 \%$ of the patients with CAP $(\mathrm{p}=0.009)$. The frequencies of the organisms isolated in both groups are shown in Table 2. Streptococcus pneumoniae was the major pathogen in both groups, and $S$. aureus, $P$. aeruginosa, and polymicrobial pathogens were isolated more frequently from patients with HCAP than from those with CAP. M. tuberculosis was identified at an over- all frequency of $6.4 \%$, with no significant group difference $(\mathrm{p}=0.65)$.

After adjusting for age, comorbidities, and the HCAP risk group, the use of antibiotics within 90 days and tube feeding were significantly correlated with the occurrence of MDR pathogens (AOR, 8.03; 95\% CI, 2.46-26.21; $\mathrm{p}=0.001$ and AOR, 9.42; 95\% CI, 3.40-26.13; $\mathrm{p}<0.0001$, respectively).

The most frequently prescribed initial antibiotic regimen was antipseudomonal $\beta$-lactam plus fluoroquinolone (48.6\%; e.g., piperacillin/tazobactam $4.5 \mathrm{~g}$ q8hr plus levofloxacin 750 mg q24hr) for HCAP and third and fourth-generation cephalosporins and macrolides (64.4\%; e.g., ceftriaxone $2 \mathrm{~g}$ q24hr plus azithromycin $500 \mathrm{mg}$ q24hr) for CAP (data not shown). In addition, vancomycin was used in 15 patients with HCAP (7.2\%) and eight patients with CAP (2.9\%) (Table 3$)$.

\section{Severity of pneumonia and clinical outcomes}

As shown Table 1, initial severities as measured by the PSI and CURB-65 were significantly higher in patients with HCAP than in those with CAP, and a probable case of aspiration pneumonia was more frequent in patients with HCAP.

The overall 30-day mortality rate was $9.9 \%$. In a univariate analysis, HCAP was associated with not only an increased 30-day mortality rate (HCAP, 16.3\%; CAP, 5.1\%; $\mathrm{p}<0.0001$ ) but also an increased rate of mechanical ventilation or vasopressor support (HCAP, 20.7\%; CAP, 9.5\%; $\mathrm{p}<0.0001$ ). The age distribution was one of the strongest risk factors for mortality. After excluding six unusually young cases (extreme values), the minimum age in the HCAP group was 42 years. Thus, we limited our study patients to those aged $\geq 42$ years to reduce the effect of age. Forty-nine patients ( 6 with HCAP and 43

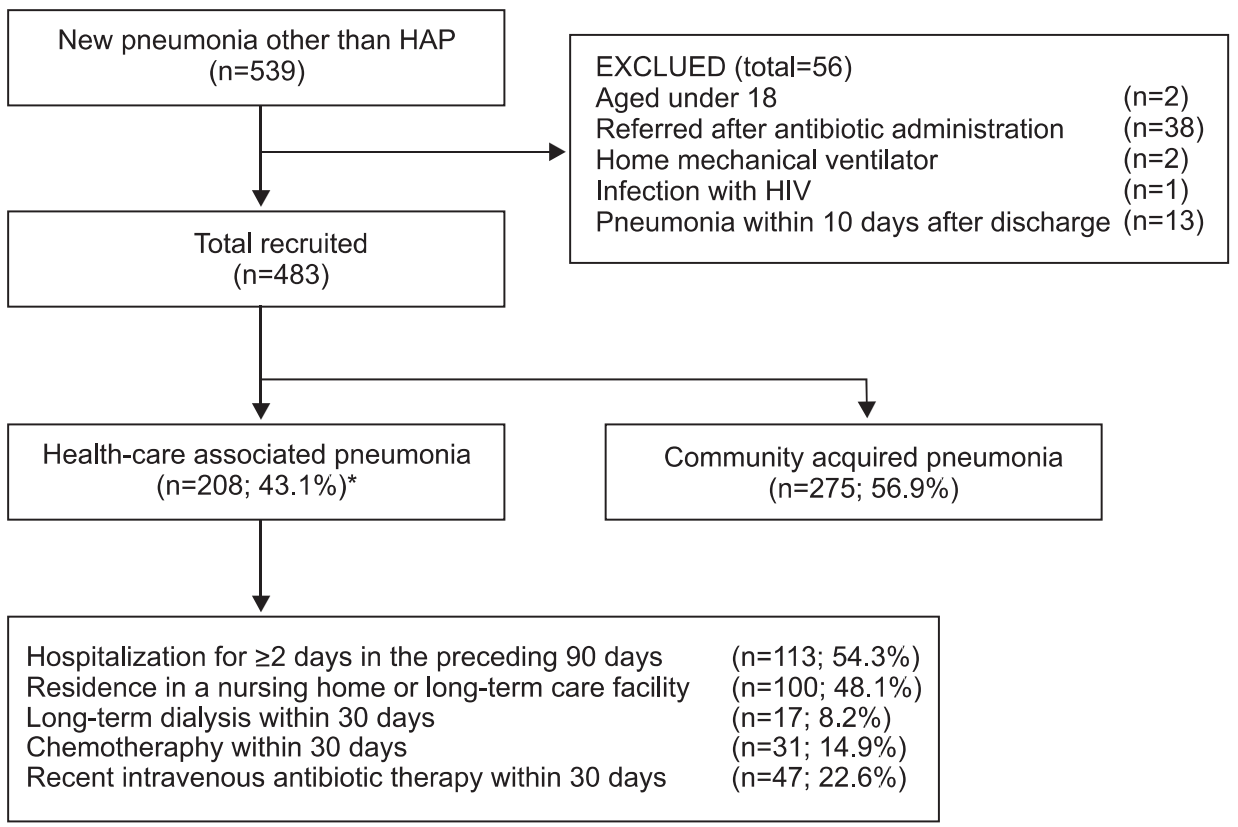

Figure 1. Flow diagram of the study population. *Including overlapping cases. HAP: hospital-acquired pneumonia; HIV: human immunodeficiency virus. 
Table 1. Baseline demographics and illness severity

\begin{tabular}{|c|c|c|c|}
\hline Variable & HCAP patients $(n=208)$ & CAP patients $(n=275)$ & p-value \\
\hline Male gender & $133(63.9)$ & $153(55.6)$ & 0.066 \\
\hline Age, yr & $74(65-81)$ & $69(52-78)$ & $<0.0001$ \\
\hline Age $>65 \mathrm{yr}$ & $157(75.5)$ & $157(57.1)$ & $<0.0001$ \\
\hline $\mathrm{BMI}, \mathrm{kg} / \mathrm{m}^{2}$ & $21.7(18.6-23.4)$ & $21.9(19.5-24.7)$ & 0.01 \\
\hline \multicolumn{4}{|l|}{ Comorbidities } \\
\hline Malignancy & $63(30.3)$ & $31(11.3)$ & $<0.0001$ \\
\hline Chronic lung disease & $39(18.8)$ & $52(18.9)$ & 0.965 \\
\hline Congestive heart failure & $21(10.1)$ & $13(4.7)$ & 0.022 \\
\hline Chronic kidney disease & $25(12.0)$ & $17(6.2)$ & 0.024 \\
\hline Chronic liver disease & $13(6.3)$ & $14(5.1)$ & 0.583 \\
\hline Cerebrovascular disease & $73(35.1)$ & $50(18.2)$ & $<0.0001$ \\
\hline Dementia & $58(27.9)$ & $13(4.7)$ & $<0.0001$ \\
\hline Diabetes mellitus & $48(23.1)$ & $44(16.0)$ & 0.05 \\
\hline \multicolumn{4}{|l|}{ Clinical parameters } \\
\hline Confusion & $49(23.6)$ & $25(9.1)$ & $<0.0001$ \\
\hline Systolic $\mathrm{BP}<90 \mathrm{~mm}$ Hg or Diastolic $\mathrm{BP} \leq 60 \mathrm{~mm} \mathrm{Hg}$ & $69(33.2)$ & $55(20.0)$ & 0.001 \\
\hline Respiratory rate $\geq 30$ breaths $/ \mathrm{min}$ & $35(16.8)$ & $44(16.0)$ & 0.808 \\
\hline $\mathrm{SpO}_{2} \leq 90 \%$ or $\mathrm{PaO}_{2} \leq 60 \mathrm{~mm} \mathrm{Hg}$ & $100(48.1)$ & $99(36.0)$ & 0.008 \\
\hline \multicolumn{4}{|l|}{ Laboratory findings } \\
\hline $\mathrm{pH}<7.35^{*}$ & $16 / 176(9.1)$ & $17 / 183(9.3)$ & 0.948 \\
\hline BUN>19 mg/dL & $123(59.1)$ & $99(36.0)$ & $<0.0001$ \\
\hline $\mathrm{Na}<130 \mathrm{mmol} / \mathrm{L}$ & $19(9.1)$ & $8(2.9)$ & 0.003 \\
\hline Glucose $\geq 250 \mathrm{mg} / \mathrm{dL}$ & $17(8.2)$ & $15(5.5)$ & 0.234 \\
\hline Hematocrit $<30 \%$ & $59(28.4)$ & $22(8.0)$ & $<0.0001$ \\
\hline $\mathrm{ESR}, \mathrm{mm} / \mathrm{hr}$ & $68(44-101)$ & $61(39-96)$ & 0.467 \\
\hline CRP, mg/dL & $12.04(6.31-19.98)$ & $10.51(4.32-18.63)$ & 0.063 \\
\hline Procalcitonin & $0.43(0.13-1.91)$ & $0.16(0.09-0.75)$ & 0.130 \\
\hline Probable aspiration pneumonia & $80(38.5)$ & $26(9.5)$ & $<0.0001$ \\
\hline Tube feeding & $29(13.9)$ & $8(2.9)$ & $<0.0001$ \\
\hline Severe sepsis & $81(38.9)$ & $56(20.4)$ & $<0.0001$ \\
\hline ICU admission & $61(29.3)$ & $36(13.1)$ & $<0.0001$ \\
\hline Pneumonia Severity Index score & $112(100-143)$ & $82(57-111)$ & $<0.0001$ \\
\hline High risk group ( $\geq \mathrm{IV})$ & $170(81.7)$ & $110(40.0)$ & $<0.0001$ \\
\hline CURB-65 & $2(1-3)$ & $1(0-2)$ & $<0.0001$ \\
\hline High risk group ( $\geq 3$ ) & $77(37.0)$ & $56(20.4)$ & $<0.0001$ \\
\hline
\end{tabular}

Values are presented as number (\%) or median (25th-75th percentile).

*Initial arterial blood gas analysis was performed in 359 (74.3\%) of the study patients.

HCAP: healthcare-associated pneumonia; CAP: community-acquired pneumonia; BMI: body mass index; BP: blood pressure; BUN: blood urea nitrogen; ESR: erythrocyte sedimentation rate; CRP: C-reactive protein; ICU: intensive care unit.

with CAP) were excluded, and there were no 30-day mortalities among these patients. In this limited study population, the univariate OR for HCAP and 30-day mortality was 3.15 (95\%
CI, 1.64-6.06; $\mathrm{p}<0.0001$ ) (Table 4). However, after adjusting for age, sex, comorbidities, initial severity (CURB-65 score) and use of antipseudomonal antibiotics, the association between 
Table 2. Microbes identified in the HCAP and CAP groups

\begin{tabular}{|c|c|c|c|}
\hline Microbe & HCAP patients $(n=199)^{*}$ & CAP patients $(n=268) *$ & p-value \\
\hline Gram-positive pathogens & $67(33.7)$ & $59(22.0)$ & 0.005 \\
\hline Streptococcus pneumoniae & $34(17.1)$ & $44(16.4)$ & 0.85 \\
\hline Staphylococcus aureus & $32(16.1)$ & $10(3.7)$ & $<0.0001$ \\
\hline MSSA & $16(8.0)$ & $7(2.6)$ & 0.007 \\
\hline MRSA & $16(8.0)$ & $3(1.1)$ & 0.0001 \\
\hline Streptococci other than S. pneumoniae & $1(0.5)$ & $5(1.9)$ & 0.2 \\
\hline Gram-negative pathogens & $29(14.6)$ & $19(7.1)$ & 0.008 \\
\hline Pseudomonas species & $19(9.5)$ & $10(3.7)$ & 0.01 \\
\hline Klebsiella species & $4(2.0)$ & $6(2.2)$ & 0.87 \\
\hline ESBLs & $2(1.0)$ & $1(0.4)$ & \\
\hline Escherichia coli & 0 & 0 & \\
\hline ESBLs & 0 & 0 & \\
\hline Moraxella catarrhalis & $2(1.0)$ & $1(0.4)$ & \\
\hline Haemophilus influenzae & 0 & $1(0.4)$ & \\
\hline Bordetella pertussis & 0 & $1(0.4)$ & \\
\hline Enterobacter species & $2(1.0)$ & 0 & \\
\hline Proteus mirabilis & 0 & 0 & \\
\hline Acinetobacter species & $1(0.5)$ & 0 & \\
\hline Stenotrophomonas maltophilia & 0 & 0 & \\
\hline Burkholderia cepacia & $1(0.5)$ & 0 & \\
\hline Other Gram-negative bacteria $^{\dagger}$ & $1(0.5)$ & 0 & \\
\hline \multicolumn{4}{|l|}{ Atypical pathogens } \\
\hline Chlamydophila pneumoniae & 0 & 0 & \\
\hline Mycoplasma pneumoniae & 0 & $7(2.6)$ & 0.02 \\
\hline Legionella pneumophila & 0 & 0 & \\
\hline Influenza virus & $2(1.0)$ & $4(1.5)$ & 0.65 \\
\hline Mycobacterium tuberculosis & $12(6.0)$ & $19(7.1)$ & 0.65 \\
\hline Nontuberculous mycobacteria & 0 & $1(0.4)$ & \\
\hline Pneumocystis jiroveci & $1(0.5)$ & 0 & \\
\hline Aspergillosis species & $1(0.5)$ & 0 & \\
\hline Anaerobes & 0 & 0 & \\
\hline Polymicrobial pathogens & 10/102 (9.8) & $4 / 105(3.8)$ & 0.009 \\
\hline MDR pathogens & $36(18.1)$ & $13(4.9)$ & $<0.0001$ \\
\hline No pathogen identified & $97(48.7)$ & $163(60.8)$ & 0.009 \\
\hline
\end{tabular}

Values are presented as number (\%).

*Nine HCAP and seven CAP patients were excluded from the analysis because of missing data. ${ }^{\dagger}$ Unidentified Gram-negative pathogen in the blood culture.

HCAP: healthcare-associated pneumonia; CAP: community-acquired pneumonia; MSSA: methicillin-sensitive Staphylococcus aureus; MRSA: methicillin-resistant Staphylococcus aureus; ESBL: extended-spectrum $\beta$-lactamase; MDR: multidrug-resistant.

HCAP and the 30-day mortality rate became non-significant (OR, 1.98; 95\% CI, 0.94-4.18; p=0.167) (Table 5). The HosmerLemeshow test indicated a good fit for both models $(\mathrm{p}>0.05)$.
Inappropriate initial antimicrobial treatment was significantly higher in patients with HCAP than in those with CAP ( $\mathrm{p}=0.047)$, but it did not correlate with 30-day mortality 
Table 3. Antibiotic treatment and clinical outcomes of patients with HCAP and CAP

\begin{tabular}{|c|c|c|c|}
\hline Variable & HCAP patients $(n=208)$ & CAP patients $(n=275)$ & p-value \\
\hline \multicolumn{4}{|l|}{ Initial antibiotic therapy } \\
\hline Monotherapy & $52(25.5)$ & $46(16.7)$ & \\
\hline Amino-penicillins & 0 & $2(0.7)$ & \\
\hline Cephalosporin & 0 & $7(2.5)$ & \\
\hline Antipseudomonal penicillins & $22(10.6)$ & $10(3.6)$ & \\
\hline Respiratory fluroquinolone & $26(12.5)$ & $26(9.5)$ & \\
\hline Carbapenem & $4(1.9)$ & $1(0.4)$ & \\
\hline Combination therapy* & $156(75.0)$ & $229(83.3)$ & \\
\hline Antipseudomonal b-lactams+fluroquinolone & $101(48.6)$ & $22(8.0)$ & \\
\hline Antipseudomonal b-lactams+macrolide & $13(6.3)$ & $8(2.9)$ & \\
\hline b-Lactams+macrolide & $34(16.3)$ & $177(64.4)$ & \\
\hline b-Lactams+clindamycin & $3(1.4)$ & $13(4.7)$ & \\
\hline Others & $5(2.4)$ & $9(3.3)$ & \\
\hline Inappropriate antibiotic treatment & $31 / 102(30.4)$ & $24 / 105(22.9)$ & 0.220 \\
\hline \multicolumn{4}{|l|}{ Clinical outcomes } \\
\hline 30-Day mortality & $34(16.3)$ & $14(5.1)$ & $<0.0001$ \\
\hline ICU admission & $61(29.3)$ & $36(13.1)$ & $<0.0001$ \\
\hline Use of mechanical ventilator & $17(8.2)$ & $15(5.5)$ & 0.234 \\
\hline Hospital stay, days & $9(6-15)$ & $7(5-10)$ & $<0.0001$ \\
\hline
\end{tabular}

Values are presented as number (\%).

*Additional vancomycin was used in fifteen HCAP and eight CAP patients.

HCAP: healthcare-associated pneumonia; CAP: community-acquired pneumonia; ICU: intensive care unit.

Table 4. Univariate analysis of the predictors of 30-day mortality

\begin{tabular}{|lccc|}
\hline & Odds ratio & $\mathbf{9 5 \%}$ CI & p-value \\
\hline Age & - & - & - \\
Male & 1.38 & $0.76-2.51$ & 0.29 \\
HCAP & 3.64 & $1.90-6.99$ & $<0.001$ \\
Malignancy & 1.623 & $0.82-3.21$ & 0.16 \\
Chronic lung disease & & & \\
Congestive heart failure & 2.58 & $1.06-6.29$ & 0.03 \\
Chronic kidney disease & 0.43 & $0.10-1.835$ & 0.41 \\
Chronic liver disease & 0.71 & $0.16-3.11$ & 0.65 \\
Cerebrovascular disease & 1.70 & $0.91-3.20$ & 0.10 \\
CURB-65 stage & & & \\
\hline \multicolumn{1}{l}{ Low (0-1) } & 1.00 & & \\
\hline Intermediate (2) & 4.52 & $1.36-14.99$ & 0.014 \\
\hline $\begin{array}{l}\text { High (3-5) } \\
\text { Tube feeding }\end{array}$ & 20.09 & $6.95-58.06$ & $<0.001$ \\
\hline $\begin{array}{l}\text { Use of antipseudomonal } \\
\text { antibiotics }\end{array}$ & 2.80 & $1.20-6.53$ & 0.01 \\
\hline
\end{tabular}

CI: confidence interval; HCAP: healthcare-associated pneumonia.
Table 5. Multivariate analysis of the predictors of 30-day mortality

\begin{tabular}{|lccc|}
\hline & Odds ratio & 95\% CI & p-value \\
\hline Age & 1.03 & $0.98-1.07$ & 0.237 \\
Male & 1.70 & $0.80-3.59$ & 0.167 \\
HCAP & 1.98 & $0.94-4.18$ & 0.074 \\
Malignancy & 1.64 & $0.71-3.84$ & 0.250 \\
Chronic lung disease & 0.21 & $0.04-1.03$ & 0.054 \\
Congestive heart failure & 2.08 & $0.67-6.41$ & 0.203 \\
Chronic kidney disease & 0.41 & $0.81-2.10$ & 0.286 \\
Chronic liver disease & 0.94 & $0.19-4.70$ & 0.074 \\
Cerebrovascular disease & 0.81 & $0.37-1.80$ & 0.611 \\
CURB-65 stage & & & \\
\hline \multicolumn{1}{l}{ Low (0-1) } & 1.00 & & \\
\multicolumn{1}{|l}{ Intermediate (2) } & 3.06 & $0.82-11.43$ & 0.096 \\
\hline High (3-5) & 12.92 & $3.84-43.48$ & $<0.001$ \\
Tube feeding & 1.58 & $0.50-4.99$ & 0.437 \\
\hline Use of antipseudomonal & 0.42 & $0.08-2.25$ & 0.311 \\
antibiotics & & & \\
\hline
\end{tabular}

CI: confidence interval; HCAP: healthcare-associated pneumonia. 
$(\mathrm{p}=0.293)$.

Among patients with HCAP, the use of antipseudomonal antibiotics as an initial therapy was not associated with a decrease in 30-day mortality in either the univariate $(\mathrm{p}=0.09)$ or multivariate analysis (AOR, 1.67; 95\% CI, 0.72-3.90; $\mathrm{p}=0.24$ ). Of the HCAP risk factors, only residence in a nursing home was independently associated with an increase in 30-day mortality (AOR, 4.46; 95\% CI, 1.37-13.90; $\mathrm{p}=0.013$ ).

\section{Discussion}

HCAP is a new category of pneumonia with potential involvement of MDR pathogens and is distinct from CAP. The 2005 ATS/IDSA guidelines concluded that most patients with HCAP are at risk for MDR pathogen infection. Thus, broad spectrum therapy with triple antibiotics is recommended for the patients with $\mathrm{HCAP}^{2}$. Despite these recommendations, the evidence specifically related to patients with HCAP is weak, and no randomized controlled trials have been conducted. Of the 294 references cited by the ATS/IDSA guidelines, only seven originally related to HCAP, and these were about nursing home-associated pneumonia ${ }^{8-10}$. Kollef et al. ${ }^{1}$ published a large retrospective HCAP data series in the United States, shortly after the guidelines were introduced. Among patients with HCAP, about 50\% had methicillin-resistant Staphylococcus aureus (MRSA) or P. aeruginosa, and overall mortality was similar to that of patients with HAP (19.8\% and $18.8 \%$, respectively). These findings were consistent in several subsequent United States studies ${ }^{11-14}$. However, many disagreements have occurred among physicians, and recently reported studies from countries other than the United States have suggested that the frequency of MDR pathogens is more similar to that with $\mathrm{CAP}^{15-20}$

Our study aimed to determine the differences in etiology and outcomes between patients with HCAP and those with CAP, and to clarify antibiotic strategies for HCAP in a tertiary teaching hospital in Jeju, Korea. HCAP accounted for $43.1 \%$ of hospitalized patients with pneumonia in the present study, and the incidence of HCAP was higher than that in previous studies (17.3-38.0\%) $)^{1,15,21,22}$. The definition of HCAP was widely variable in previous studies, and some studies included only culture-positive patients. Our analysis included only hospitalized pneumonia cases and studies performed at a referral hospital. Because of the retrospective nature of this study, the true incidence of HCAP cannot be estimated. However, it is of greater importance that more than one-third of hospitalized pneumonia cases may have MDR pathogens.

In the present study, the overall 30-day mortality rate was 9.9\%. As in previous studies, the mortality rate of patients with HCAP was three times that of patients with CAP. However, no relationship between HCAP and mortality was observed after adjustments for confounding variables. Investigating the underlying reasons for the increased mortality was complicated for several reasons. First, patients with HCAP were older and had more frequent comorbidities. As these two factors are powerful prognostic factors for pneumonia, other factors would be easily diluted in a retrospective study. In addition, it is uncertain whether MDR pathogens and inappropriate antibiotics were directly associated with higher mortality in patients with HCAP. Previous data on critically ill patients have shown that inappropriate antibiotic treatment is related to higher mortality ${ }^{23-25}$. However, outcomes and initial extended antibiotics are not simply defined in patients with HCAP. Rello et al. ${ }^{26}$ reported that pneumococcal HCAP results in excess mortality that is independent of bacterial susceptibility. These differences in outcomes were probably due to differences in age, comorbidities, and intensive care unit admission criteria, rather than therapeutic decisions. Recent studies from the United States $^{27}$ and Canada ${ }^{28}$ have suggested that therapy consistent with the 2005 ATS/IDSA guidelines fails to decrease mortality and in some cases, tends to correlate with increased mortality.

About $40 \%$ of the patients in the HCAP group had more than two risk factors. It is unclear whether each healthcare environment had the same risk for MDR pathogens, or whether there are multiple risk factors for MDR pathogens. According to the current definition, HCAP is a distillation of multiple risk factors; thus, each patient must be considered individually, particularly with regard to performance status. For example, the risk for infection with MDR pathogens in a nursing home resident who has dementia but maintains daily self-care activities is different from the risk in a patient who is in a vegetative state with a tracheostomy and a feeding tube.

The ATS/IDSA guidelines for the empirical treatment of HCAP indicate that MRSA should be treated with either vancomycin or linezolid ${ }^{2,19}$. However, the impact of this recommendation on clinical outcomes, including mortality, is limited, and the prevalence of MRSA varies ${ }^{29,30}$. In the present study, MRSA was identified in $7.7 \%$ of the patients with HCAP, and $7.2 \%$ of the patients with HCAP were initially prescribed vancomycin. We could not analyze clinical outcomes and vancomycin use because the incidence of MRSA and frequency of vancomycin administration were too low.

M. tuberculosis was isolated from $5.8 \%$ of patients with HCAP and $6.9 \%$ of patients with CAP. In most previous HCAP studies, $M$. tuberculosis was not considered a major pathogen and was not evaluated. According to our data, M. tuberculosis is not rare in patients with HCAP, and acid fast bacilli staining and cultures should be considered in the initial diagnostic work-up in M. tuberculosis-endemic areas ${ }^{31,32}$.

Although study did not establish a clear guideline to choose antibiotics, it is important to know local epidemiologic data.

We found causative microorganisms in hospitalized pneumonia cases except those of HAP. Significantly more Pseudomonas species were identified in the HCAP group than in the 
CAP group, yet fewer than $10 \%$ of the Pseudomonas pneumonia cases occurred in the HCAP group. This suggests that the use of double or triple broad-spectrum antibiotics may not be justified, although we did not seek to establish clear guidelines for choosing antibiotics in the present study. After adjusting for potential confounders, the 30-day mortality rate was not significantly higher in the HCAP group compared with the CAP group. The observed higher mortality in patients with HCAP may be attributable mainly to the age of the patient and the initial clinical severity of the disease. While an unverified, broad definition of HCAP may obscure the importance of healthcare-associated MDR infections, it is nevertheless important to understand local epidemiological data on MDR infections. Unfortunately, few studies have evaluated HCAP epidemiology in Korea ${ }^{33,34}$.

Our study had some limitations that warrant consideration. First, because this was a retrospective study, unintentional data loss might have influenced the HCAP classification, despite our careful review of medications and hospitalization. We did not collect data on premorbid performance status or treatment limitations such as do not resuscitate orders. Therefore, we could not evaluate how performance status and treatment restrictions might have influenced clinical outcomes. Second, there are some limitations regarding available laboratory data. Haemophilus influenza is a major pathogen of adult pneumonia, but reported culture-positive results were extremely rare. No follow-up antibody titer tests were performed in any of the suspected M. pneumoniae patients. Third, consideration of special conditions such as tracheostomy or a feeding tube in situ was lacking.

In conclusion, HCAP was a common cause of hospital admissions and was associated with a high mortality rate. However, the higher mortality rate in patients with HCAP was not related to MDR pathogens. Thus, broad-spectrum antibiotics should be used with caution in these patients. The regional variations in the incidence and microbiology of HCAP emphasize the importance of understanding the local epidemiology. Furthermore, heterogeneous HCAP data may be confusing, and the HCAP concept should be carefully defined. A welldesigned substantial study is imminent.

\section{References}

1. Kollef MH, Shorr A, Tabak YP, Gupta V, Liu LZ, Johannes RS. Epidemiology and outcomes of health-care-associated pneumonia: results from a large US database of culture-positive pneumonia. Chest 2005;128:3854-62.

2. American Thoracic Society; Infectious Diseases Society of America. Guidelines for the management of adults with hospital-acquired, ventilator-associated, and healthcare-associated pneumonia. Am J Respir Crit Care Med 2005;171:388416.
3. Manell LA, Wunderink R. Chapter 257. Pneumonia. In: LongoDL, Fauci AS, Kasper DL, Hauser SL, Jameson JL, Loscalzo J, editors. Harrison's principles of internal medicine. 18th ed. New York: McGraw-Hill Co. Inc.; 2012. p. 2130-41.

4. Carratala J, Fernandez-Sabe N, Ortega L, Castellsague X, Roson B, Dorca J, et al. Outpatient care compared with hospitalization for community-acquired pneumonia: a randomized trial in low-risk patients. Ann Intern Med 2005;142:165-72.

5. Mandell LA, Wunderink RG, Anzueto A, Bartlett JG, Campbell GD, Dean NC, et al. Infectious Diseases Society of America/ American Thoracic Society consensus guidelines on the management of community-acquired pneumonia in adults. Clin Infect Dis 2007;44 Suppl 2:S27-72.

6. Lim WS, van der Eerden MM, Laing R, Boersma WG, Karalus $\mathrm{N}$, Town GI, et al. Defining community acquired pneumonia severity on presentation to hospital: an international derivation and validation study. Thorax 2003;58:377-82.

7. Fine MJ, Auble TE, Yealy DM, Hanusa BH, Weissfeld LA, Singer DE, et al. A prediction rule to identify low-risk patients with community-acquired pneumonia. N Engl J Med 1997;336:243-50.

8. Mylotte JM. Nursing home-acquired pneumonia. Clin Infect Dis 2002;35:1205-11.

9. Hutt E, Kramer AM. Evidence-based guidelines for management of nursing home-acquired pneumonia. J Fam Pract 2002;51:709-16.

10. Lim WS, Macfarlane JT. A prospective comparison of nursing home acquired pneumonia with community acquired pneumonia. Eur Respir J 2001;18:362-8.

11. Micek ST, Kollef KE, Reichley RM, Roubinian N, Kollef MH. Health care-associated pneumonia and community-acquired pneumonia: a single-center experience. Antimicrob Agents Chemother 2007;51:3568-73.

12. Schreiber MP, Chan CM, Shorr AF. Resistant pathogens in nonnosocomial pneumonia and respiratory failure: is it time to refine the definition of health-care-associated pneumonia? Chest 2010;137:1283-8.

13. Zilberberg MD, Shorr AF, Micek ST, Mody SH, Kollef MH. Antimicrobial therapy escalation and hospital mortality among patients with health-care-associated pneumonia: a singlecenter experience. Chest 2008;134:963-8.

14. Fujitani S, Sun HY, Yu VL, Weingarten JA. Pneumonia due to Pseudomonas aeruginosa: part I: epidemiology, clinical diagnosis, and source. Chest 2011;139:909-19.

15. Carratala J, Mykietiuk A, Fernandez-Sabe N, Suarez C, Dorca J, Verdaguer R, et al. Health care-associated pneumonia requiring hospital admission: epidemiology, antibiotic therapy, and clinical outcomes. Arch Intern Med 2007;167:1393-9.

16. Lim WS, Baudouin SV, George RC, Hill AT, Jamieson C, Le Jeune I, et al. BTS guidelines for the management of community acquired pneumonia in adults: update 2009. Thorax 2009;64 Suppl 3:iiil-55.

17. Woodhead M, Blasi F, Ewig S, Huchon G, Ieven M, Ortqvist A, 
et al. Guidelines for the management of adult lower respiratory tract infections. Eur Respir J 2005;26:1138-80.

18. Chalmers JD, Taylor JK, Singanayagam A, Fleming GB, Akram AR, Mandal P, et al. Epidemiology, antibiotic therapy, and clinical outcomes in health care-associated pneumonia: a UK cohort study. Clin Infect Dis 2011;53:107-13.

19. Kollef MH, Morrow LE, Baughman RP, Craven DE, McGowan JE Jr, Micek ST, et al. Health care-associated pneumonia (HCAP): a critical appraisal to improve identification, management, and outcomes: proceedings of the HCAP Summit. Clin Infect Dis 2008;46 Suppl 4:S296-334.

20. Lambert ML, Suetens C, Savey A, Palomar M, Hiesmayr M, Morales I, et al. Clinical outcomes of health-care-associated infections and antimicrobial resistance in patients admitted to European intensive-care units: a cohort study. Lancet Infect Dis 2011;11:30-8.

21. Venditti M, Falcone M, Corrao S, Licata G, Serra P; Study Group of the Italian Society of Internal Medicine. Outcomes of patients hospitalized with community-acquired, health care-associated, and hospital-acquired pneumonia. Ann Intern Med 2009;150:19-26.

22. Shindo Y, Sato S, Maruyama E, Ohashi T, Ogawa M, Hashimoto N, et al. Health-care-associated pneumonia among hospitalized patients in a Japanese community hospital. Chest 2009;135:633-40.

23. Kollef MH. Inadequate antimicrobial treatment: an important determinant of outcome for hospitalized patients. Clin Infect Dis 2000;31 Suppl 4:S131-8.

24. Kollef MH, Sherman G, Ward S, Fraser VJ. Inadequate antimicrobial treatment of infections: a risk factor for hospital mortality among critically ill patients. Chest 1999;115:462-74.

25. Garnacho-Montero J, Garcia-Garmendia JL, Barrero-Almodovar A, Jimenez-Jimenez FJ, Perez-Paredes C, Ortiz-Leyba C. Impact of adequate empirical antibiotic therapy on the outcome of patients admitted to the intensive care unit with sepsis. Crit Care Med 2003;31:2742-51.

26. Rello J, Lujan M, Gallego M, Valles J, Belmonte Y, Fontanals
D, et al. Why mortality is increased in health-care-associated pneumonia: lessons from pneumococcal bacteremic pneumonia. Chest 2010;137:1138-44.

27. Kett DH, Cano E, Quartin AA, Mangino JE, Zervos MJ, Peyrani $\mathrm{P}$, et al. Implementation of guidelines for management of possible multidrug-resistant pneumonia in intensive care: an observational, multicentre cohort study. Lancet Infect Dis 2011;11:181-9.

28. Grenier C, Pepin J, Nault V, Howson J, Fournier X, Poirier MS, et al. Impact of guideline-consistent therapy on outcome of patients with healthcare-associated and communityacquired pneumonia. J Antimicrob Chemother 2011;66:161724.

29. El Solh AA, Pietrantoni C, Bhat A, Bhora M, Berbary E. Indicators of potentially drug-resistant bacteria in severe nursing home-acquired pneumonia. Clin Infect Dis 2004;39:474-80.

30. Micek ST, Reichley RM, Kollef MH. Health care-associated pneumonia (HCAP): empiric antibiotics targeting methicillinresistant Staphylococcus aureus (MRSA) and Pseudomonas aeruginosa predict optimal outcome. Medicine (Baltimore) 2011;90:390-5.

31. Jensen PA, Lambert LA, Iademarco MF, Ridzon R; CDC. Guidelines for preventing the transmission of Mycobacterium tuberculosis in health-care settings, 2005. MMWR Recomm Rep 2005;54:1-141.

32. Feng JY, Fang WF, Wu CL, Yu CJ, Lin MC, Ku SC, et al. Concomitant pulmonary tuberculosis in hospitalized healthcareassociated pneumonia in a tuberculosis endemic area: a multi-center retrospective study. PLoS One 2012;7:e36832.

33. Park HK, Song JU, Um SW, Koh WJ, Suh GY, Chung MP, et al. Clinical characteristics of health care-associated pneumonia in a Korean teaching hospital. Respir Med 2010;104:1729-35.

34. Jung JY, Park MS, Kim YS, Park BH, Kim SK, Chang J, et al. Healthcare-associated pneumonia among hospitalized patients in a Korean tertiary hospital. BMC Infect Dis 2011;11: 61. 